Ахметқұл Малика, Магистрант Воронежский институт высоких технологий

г. Воронеж, Россия

E-mail: malika_92.art@mail.ru ORCID ID 0000-0002-5316-2105

\title{
ОСОБЕННОСТИ МОДЕЛИ ЧЕЛОВЕЧЕСКОГО КАПИТАЛА В ОБЛАСТИ МЕДИЦИНЫ И ФАКТОРЫ, ВЛИЯЮЩИЕ НА ЕЕ ФОРМИРОВАНИЕ
}

Malika Akhmetkul, Master's Degree student Voronezh Institute of High Technologies E-mail: malika_92.art@mail.ru ORCID ID 0000-0002-5316-2105

\section{FEATURES OF THE HUMAN CAPITAL MODEL IN THE FIELD OF MEDICINE AND THE FACTORS INFLUENCING ITS FORMATION}

Annotation: This article is devoted to a research of the informative characteristic of the human capital model in the field of medicine. Optimal formation of the human capital model in the conditions of digital transformation is possible only at interaction of personal, professional and moral qualities of the employee. At the same time, exact definition of the factors influencing quality of the human capital will allow to develop the development strategy more competently and increase effectiveness of activity of the company, its competitiveness, and satisfaction of personnel.

Keywords: human capital, general and specific characteristics of medical professional, competency system.

Аннотация: Настоящая статья посвящена исследованию содержательной характеристики модели человеческого капитала в области медицины, оптимальное формирование которой в условиях ицифровой трансформации возможно лишь при взаимодействии личностных, профессиональных и нравственных качеств сотрудника. При этом, точное определение факторов, влияюших на качество человеческого капитала, позволит более грамотно разрабатывать стратегию развития, повысит результативность деятельности компании, ее конкурентоспособность, удовлетворенность персонала.

Ключевые слова: человеческий капитал, общие и особые характеристики специалистамедика, система компетенций.

На современном этапе научно-технического и социально-экономического развития отмечается возросшее значение роли человеческого фактора во всех областях деятельности. Основным фактором успеха предприятия становится человек со свойственными ему знаниями, способностями, творческими и нестандартными возможностями решать стратегические и текущие задачи при осуществлении бизнес процессов. Функционирование и развитие высококачественного трудового капитала является крайне актуальной задачей.

Многие экономисты уделяли большое внимание изучению понятия «человеческий капитал», при этом использовались различные подходы. Понятие «человеческий капитал» с точки зрения системного подхода описан в трудах Г. Б. Клейиера, он дает возможность охарактеризовать персонал во взаимосвязи с потребителями услуг [2].

Интересна точка зрения А.Г. Поршнева, который в рамках ресурсного подхода указывает прямую зависимость роста инвестиций в качество человеческого капитала и конкурентоспособности и прибыльность компании, При этом используются уникальные ресурсы, недоступные конкурентам, н частности, человеческий капитал [4].

\footnotetext{
Управление

человеческими

ресуссами
}

Материалы Международной практической интернет-конференции «Актуальные Проблемы Науки» 
Группа российских экономистов, таких как А.Я. Кибанов, Е.А. Митрофанова, И.А. Эсаулова, отмечают, что при экономическом подходе к человеческому капиталу, применима схема, разработанная Г. Беккером, которая основывается на следующих постулатах:

- человеческие способности, профессиональные навыки, знания становятся потенциалом и капиталом лишь при найме на работу, либо при получении оплаты за труд

- эффективность труда находиться в прямой зависимости от эффективности деятельности предприятия

- эффективное применение капитала неотвратимо приведет к росту доходов персонала, что является стимулом, для повышения своих знаний и способностей, для дальнейшего вложения в предприятие [3].

Теория человеческого капитала Пола Шульца определяет прямую взаимозависимость между профессиональным и экономическим развитием компании и сотрудников. Согласно данной теории, вложения в профессиональное развитие персонала выступают основополагающим условием роста результативности деятельности, что предопределяет актуальную необходимость и целесообразность данных вложений,

Развитие человеческого капитала подразумевает процесс совершенствования людских ресурсов (знаний, навыков и способностей), которыми располагает и пользуется каждый индивид в производственных либо в потребительских целях. При этом становятся особо значимыми вопросы формирования качественной модели человеческого капитала, профессионализация личности в изменяющейся социальнопрофессиональной среде в зависимости от отрасли, в которой действует компания (в частности медицине).

Под моделью человеческого капитала, в общем, и в медицинской отрасли, в частности, понимается описание качества специалиста, его профессиональных компетенций, знаний, умений и способностей решать практические задачи, выполнять необходимые функции в определенной сфере. В современных исследованиях выделяются разные модели специалистов, однако чаще всего их сводят к набору определенных личностных п профессиональных компетенций.

Личностные факторы, определяющие стратегию профессионального становления, связаны с мотивационными, когнитивными и стилевыми характеристиками специалистамедика. Основными мотивационными характеристиками являются профессиональная направленность и устойчивая система ценностных ориентаций, определяющие жизненную позицию личности специалиста. Когнитивно-интеллектуальные характеристики освоения деятельности отражают концептуальную модель профессионального развития и определяют направление профессионального становления специалиста. Стилевые особенности поведения зависят от личностнопрофессиональных ресурсов работника [5].

Развивающая организационная среда на месте профессиональной деятельности является объективным фактором профессионального становления. Она создает условия и возможности для личностного развития, организационной социализации специалистов, способствует реализации их интеллектуального и личностного потенциала.

Определяя особенность и значимость профессиональных возможностей медицинского работника, необходимо отметить те специальные знания, которыми он обладает, выступают как уровень профессиональной квалификации сотрудника.

\footnotetext{
Управление

человеческими

ресуссами
}

Материалы Международной практической интернет-конференции «Актуальные Проблемы Науки» 
Профессионализм выражается через соответствующие научные степени и звания, через категории. В определенной степени данные показатели можно считать формальными критериями оценки качества человеческого капитала в медицине и стоматологии в частности, измеряющими наличием соответствующих квалификационных документов и определенной категории, которую необходимо подтверждать.

Можно отметить, что социальная составляющая является важнейшей чертой, характеризующей человеческий капитал в медицинской сфере. Сострадательность, чуткость, желание помочь является необходимыми гранями в деятельности медицинского работника, влияющими на имидж и репутацию, как отдельного работника, так и компании в целом.

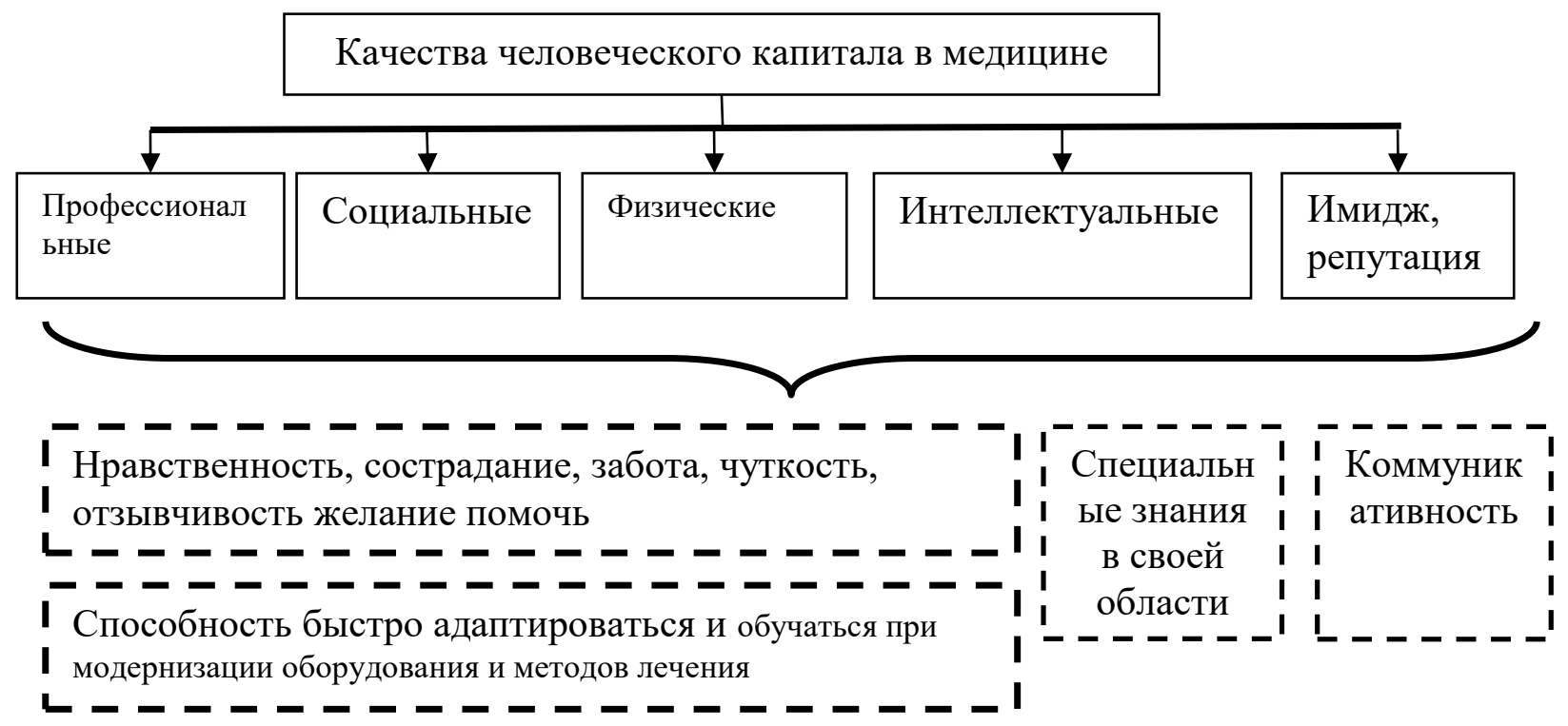

Рисунок 1 - Характеристики человеческого капитала в сфере медицины

Необходимо отметить, что требования к компетенциям специалистов-медиков в разных компаниях могут отличаться ввиду специфики сферы их деятельности. Однако, в любом случае система компетенций специалистов-медиков будет включать в себя так называемые «жесткие» компетенции (профессионализм, коммуникативность, использование современного оборудования и т.д.), которые позволят решать ему профессиональные задачи, и «гибкие» компетенции (например, умение работать в команде, креативность, пунктуальность и т.д.), которые способствуют повышен эффективности профессиональной деятельности. В соответствии с требованиями медицинских клиник к компетенциям специалистов-медиков необходимо формировать и комплекс их знаний, которые можно разделить на базовые, профессиональные и узкоспециализированные.

Исходя из вышеизложенного, модель человеческого капитала в сфере медицины включает такие общие для всех профессий компоненты как требования к компетенциям, эффективные подходы к обучению, необходимые знания и умения и особенные, отличительные от других профессий. К таким компонентам относятся нравственность, сострадание, забота, чуткость, отзывчивость желание помочь.

Максимальное проявление совокупности индивидуальных культурных, социальных, физических, духовных, интеллектуальных, профессиональных возможностей индивидуума, обладающего специальными знаниями, применением которых обеспечивается оптимальное соотношение затрат и доходов как в компании так

Управление человеческими ресуссами
Материалы Международной практической интернет-конференции «Актуальные Проблемы Науки» 
и отрасли в целом, необходимо рассматривать в совокупности с факторами, влияющими на человеческий капитал.

Точное представление о факторах, влияющих на формирование человеческого капитала, поможет увеличить эффективность контроля всей деятельности компании, что в свою очередь приведет к росту прибыли. На современном этапе развития экономики, деятельность предприятий любой отрасли, подвержена влиянию различных факторов макроэкономического характера. К ним относятся: изменения в политике страны, инфляция, валютный курс, доходы населения и прочие. Социально-экономические факторы имеют не прямое, а опосредованное влияние на характер модели человеческого капитала. Уровень образования ведет к возможности прогнозировать востребованность интеллектуального потенциала.

Кроме внешних факторов, огромное значение имеют внутренние факторы развития предприятия. От эффективной организации труда зависит максимально возможная отдача специалиста при осуществлении производственного процесса. К существенному фактору, влияющему на развитие человеческого капитала относится социально-экономическая составляющая, выражающаяся в достойной оплате труда, в соответствии с профессиональной отдачей. В частных стоматологических клиниках важно внедрение в лечебный процесс новинок стоматологического рынка (материалы, технологии, инструменты, приборы), что влечет за собой необходимость способности сотрудников быстро обучаться и часто повышать квалификационный уровень для освоения новых методов и технологий лечения. Все факторы взаимосвязаны друг с другом, изменение одних факторов ведет к соответствующему изменению других

Модель человеческого капитала представляет собой систему индикаторов, в целях получения дохода. К таким индикаторам можно отнести знания, способности, умения, навыки, возможность целесообразного использования навыков. В медицинской сфере к особенным качествам относятся нравственная составляющая и высокий уровень профессионализма.

В заключении можно отметить, что современные преобразования, происходящие в стране в последнее время, затрагивают фундаментальные основания в медицинской сфере. Решение поставленных задач требует наличия в медицине высококвалифицированных кадров, способных обеспечивать развитие инновационного потенциала. От квалификации, компетентности, человеческих и моральных качеств, обшей культуры специалиста-медика, зависит устойчивость здоровья нации и экономическое развитие страны.

\section{ЛИТЕРАТУРА}

1. Иванов В. В., Мининецкий Г.Г. Цифровая экономика: мифы, решимость, возможности. M.: PAH, 2017.

2. Клейнер Г.Б. Системная парадигма и системный менеджмент // Российский журнал менеджмента. - 2012. - № 3. - С. 28

3. Кибанов А. Я. Экономика управления персоналом: Учебник/ Кибанов А.Я., Митрофанова Е.А., Эсаулова И.А.; под ред. А.Я. Кибанова - М., 2016. - 427 с.

4. Поршнев А. Г. Управление организацией: Учебник/ Поршнев А.Г., Азоев Г.Л., Баранчеев В.П., Поршнев А.Г., Румянцева 3.П., Саломатин Н.А., 4-е изд., перераб. и доп. -М.: НИЦ ИНФРА-М, 2016. - 736 с.

5. Чигоряев К.Н. Оценка стоимости человеческого капитала на основе произведенных затрат / К.Н. Чигоряев, Н.А. Скопинцева, В.В. Ульященко // Изв. Том. политехи. ун-та. 2014. - № 6. - С. 54-56.

Управление человеческими ресуссами
Материалы Международной практической интернет-конференции «Актуальные Проблемы Науки» 